\title{
Measuring Non-Catastrophic Weather Risks for Businesses
}

\author{
Juliusz Pres \\ Department of Manager's and Engineer's Economics, West Pomeranian University of Technology, \\ Piastow 48, Szczecin 70-311, Poland. \\ E-mail: jpres@ps.pl
}

While many published articles touch on the problem of using weather derivatives as tools for non-catastrophic weather-risk management, few studies have looked at the problem of appropriate risk measurement. This paper aims to present and evaluate all available methods used to identify and estimate the impact of non-catastrophic weather upon commercial enterprises. Correctly defining these parameters fundamentally affects building weather cover. Analysis of already existing methods of weather-risk measurement for businesses, as presented in the literature, has shown a few disadvantages. This paper proposes an improved approach to weather risk measurement - one based on an extended econometric model. We have empirically tested all the methods proposed herein and present our conclusions.

The Geneva Papers (2009) 34, 425-439. doi:10.1057/gpp.2009.16

Keywords: weather risk; weather derivatives; measurement of weather risk

\section{Introduction}

Weather conditions have a crucial impact on global business activities and even have relevant effects at the macroeconomic level. In fact, as pointed out by $\mathrm{Ku},{ }^{1}$ the U.S. Department of Commerce estimates that the weather affects nearly two-thirds of U.S. companies and almost 22 per cent of the U.S. GDP. McWilliams ${ }^{2}$ has demonstrated similar evidence for the European economy. The most weather-sensitive sectors, where risk exposure is very high, include: ${ }^{3}$ energy, agriculture, construction, groceries, brewing, entertainment and transportation.

It is worth noting that volatility of weather variables is at about a similar level as the volatility of financial indices. Hence, we can easily see that there is no reason to hedge financial risk and bear weather risks. ${ }^{4}$ In other words, if a business is considered as an investment with an expected rate of return, it will always be more attractive to an investor if an unnecessary risk is reduced or fully eliminated. ${ }^{5}$ The best way for a

\footnotetext{
${ }^{1} \mathrm{Ku}(2001)$.

2 McWilliams (2004).

${ }^{3}$ Malinow (2002); Brix et al. (2005).

${ }^{4}$ Marteau and Holz (2006).

${ }^{5}$ Unnecessary risk is interpreted as risk not related to the core business and one a company should not undertake (e.g., currency risk in a shoe factory, because its core business is shoes production, not speculation on currencies).
} 

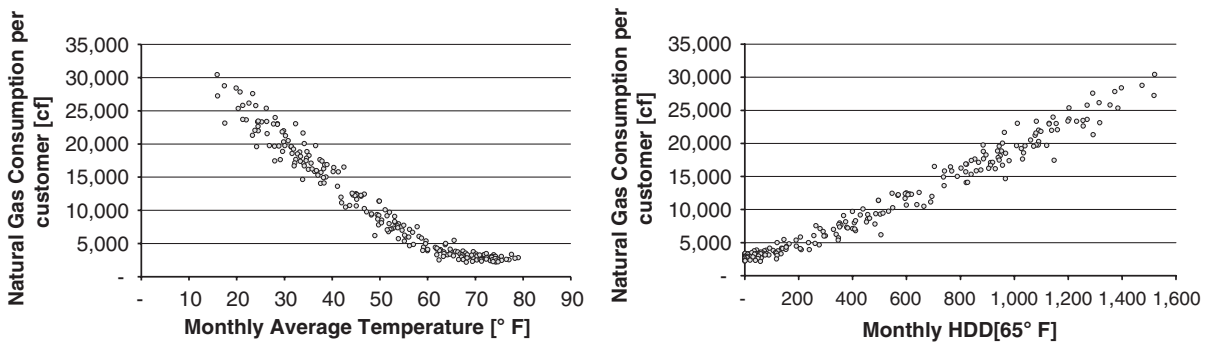

Figure 1. Residential monthly consumption of natural gas (cf) in response to monthly average temperature and monthly HDD index in the state of Illinois (U.S.), 1989-2007.

company to eliminate risks due to weather exposure is to transfer it to the capital market using weather derivatives as a weather cover. ${ }^{6}$ To do this, first, weather exposure should be defined in monetary units. This can be problematic because, apart from temperature, many other factors may affect financial results (Figure 1). Hence, this fact raises doubts as to how to measure a given company's actual weather exposure.

Constructing financial protection for a given company against unfavourable weather conditions always requires defining two parameters: type of weather exposure (one or more weather indices that have a crucial impact on financial results), and effect of weather exposure (tick value or number of standardised weather contracts) that describe the size of possible losses.

It should be mentioned here that the value (in monetary units) of one point of a given weather index or the number of standardised contracts or tick value (according to practitioners) represents the fundamental parameter in building appropriate weather cover. If this parameter is too big, a case of over-hedging results and the premium for the cover is too large. This situation quite often gives the impression that weather derivatives are expensive. If the parameter is too small, possible pay-out will not completely cover possible losses. Efficiency of weather derivatives as weather covers can then be perceived as very low. Hence, the success of coming up with the correct hedge in most cases lies in the appropriate evaluation of the weather index point. Unfortunately, the literature does not widely discuss methods of doing this. For instance, Clemmons and Radulski ${ }^{7}$ offer the "Best/ Worst" method, a very simple approach based on a comparison of weather conditions in years during which financial results were the best and the worst. Forrest ${ }^{8}$ presented a very similar approach, which we can call the "margin coefficient" method. These methods omit many important factors such as trends, customer structure and seasonality, which can lead to mistakes in estimation of weather exposure for a given company. However, the biggest disadvantage to these approaches lies in the

\footnotetext{
${ }^{6}$ Foster (2003).

${ }^{7}$ Clemmons and Radulski (2002).

${ }^{8}$ Forrest (2002).
} 
fact that they cannot be applied if a probability exists that a company will be exposed to more than one weather variable. ${ }^{9}$ As a solution for these cases, Clemmons and Radulski $^{10}$ proposed a multivariate linear regression as a more advanced approach. Nevertheless, many important factors surrounding these methods still require further study.

Hence, this paper looks at the above methods and discusses possible consequences of their application for a company that decides to use weather cover. We present an improved approach, which has been empirically tested, to cover all significant factors.

The organisation of this paper is as follows: the next section describes definitions of weather exposure and its possible forms. The third section includes basic issues of risk management and the weather-derivatives market. The fourth section contains all methods of measurement existing in the literature and also describes a new one. The results of applying the above methods on empirical data are presented in the subsequent section. The last section contains a summary and conclusions.

\section{Non-catastrophic weather risk}

In general, weather risk can be divided into two types: catastrophic and noncatastrophic. ${ }^{11}$ The first one relates to losses caused by weather events such as floods, hurricanes, drought, tornadoes, storms and hail. The second describes the financial exposure that a business may endure after weather events such as heat, cold, snow, rain and/or wind. ${ }^{12}$ While catastrophic weather events have a small chance of occurring but usually cause huge monetary losses, non-catastrophic events occur quite commonly and cause small losses and only for so-called weather-sensitive companies. As mentioned above, we will focus only on the second type of weather risk; in the first case a company can easily transfer the losses outside the company using insurance.

Non-catastrophic weather risks may have either a direct impact on a company's finances results, or both direct and indirect. A direct impact usually causes a decrease in volume of sales or creates additional costs. This type of weather risk exposes companies from agriculture, construction, groceries, brewing, entertainment, transportation, municipal services and in some cases energy. ${ }^{13}$ Indirect impact correlates with the price and/or number of such contracts that may amortise primary (volumetric) direct exposure (e.g. European Union Allowance (EUA) $\mathrm{Co}_{2}$ for electric companies) or heighten it (e.g. Renewable Energy Certificates for wind farms), and in most cases refers to the energy sector. ${ }^{14}$ Therefore, in many companies,

\footnotetext{
${ }^{9}$ Dischel (2001).

${ }^{10}$ Clemmons and Radulski (2002).

${ }^{11}$ Corbally and Dang (2002).

12 Clemmons (2002).

13 Starr-McCluer (2000); Skees (2001); Biello (2002); Connors (2003); Nicholls (2004); Saunderson (2004).

${ }^{14}$ Weinstein (2001); Wojciechowska and Jankowski (2008).
} 


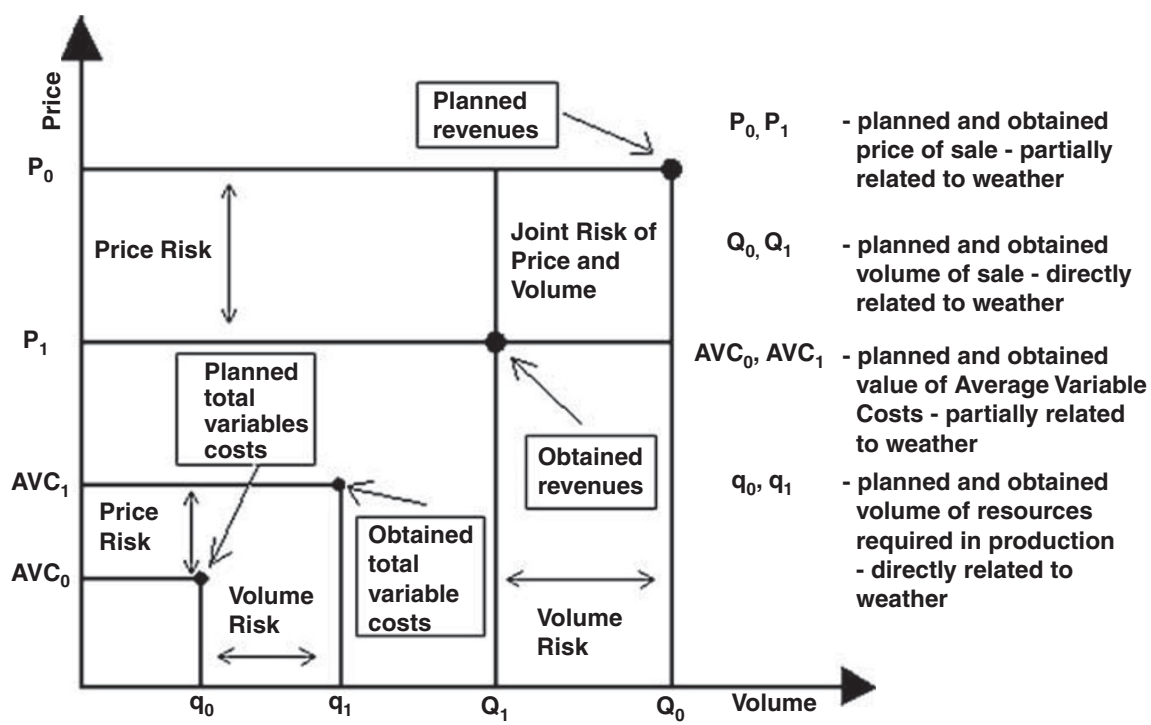

Figure 2. Possible weather conditions and their impact on company costs and revenues.

especially in the energy sector, real weather exposure is more complex and usually contains such variables as volume and price of (1) energy, (2) EUA CO 2 and "coloured certificates" and (3) resources required in energy production, mainly coal and natural gas.

Figure 2 presents a simplified interpretation of complex weather exposure in the energy sector. This figure explains that the level of both volume and price may significantly change the final total revenues and/or total variable costs for a company. In practice, especially in the energy sector, the price of energy is often partially correlated with short-term weather conditions, which causes financial results to be correlated with weather in a non-linear way. Table 1 contains an empirical example of such non-linear weather exposure for a Polish heat producer, but it is common for many companies from the energy sector.

If temperatures during the heating season are at the expected level $(\mathrm{HDD}[18]=2,500)$, there will not be any deviations from the plan. If the heating season happens to be very warm $(\mathrm{HDD}[18]=2060)$, the company will observe negative deviation in sales at the level of 2,640,000 EUR. However, after the heating season, the company will have 76,265 unused EUA as the result of lower sales and can use the remainder to amortise loss. Hence, in this case, financial results for the heating season depend on weather conditions and the market price of EUA.

Such weather exposure can be effectively eliminated if a company decides to apply weather cover where pay-out results from two parties. The first one represents a regular weather derivative where tick value is given in monetary units. The second one is called a "quanto" type, and here tick value is fixed as EUA/HDD (pictured in Table 1 as 173 EUA/HDD). Then the final pay-out from this weather cover takes into account both volumetric and price risk. 
Table 1 Empirical example of complex weather exposure during heating season, 2009 (January-April and October-December) for a Polish heat producer

\begin{tabular}{|c|c|c|c|c|c|}
\hline \multirow[t]{2}{*}{ Name } & \multicolumn{5}{|c|}{ Index of temperature during heating season - HDD [18] } \\
\hline & 2060 & 2280 & 2500 & 2720 & 2940 \\
\hline Deviation in total margin & $-2,640,000 €$ & $-1,320,000 €$ & $0 €$ & $1,320,000 €$ & $2,640,000 €$ \\
\hline Deviation in heat sale (GJ) & $-630,291$ & $-315,145$ & 0 & 315,145 & 630,291 \\
\hline Deviation in EUA consumption & 76,265 & 38,133 & 0 & $-38,133$ & $-76,265$ \\
\hline Price of EUA $\mathrm{CO}_{2}$ & \multicolumn{5}{|c|}{ Financial result on $\mathrm{EUA} \mathrm{CO}_{2}$ portfolio } \\
\hline $5 €$ & $381,326 €$ & $190,663 €$ & $0 €$ & $-190,663 €$ & $-381,326 €$ \\
\hline $10 €$ & $762,652 €$ & $381,326 €$ & $0 €$ & $-381,326 €$ & $-762,652 €$ \\
\hline $15 €$ & $1,143,978 €$ & $571,989 €$ & $0 €$ & $-571,989 €$ & $-1,143,978 €$ \\
\hline $20 €$ & $1,525,304 €$ & $762,652 €$ & $0 €$ & $-762,652 €$ & $-1,525,304 €$ \\
\hline $25 €$ & $1,906,630 €$ & $953,315 €$ & $0 €$ & $-953,315 €$ & $-1,906,630 €$ \\
\hline Price of EUA $\mathrm{CO}_{2}$ & \multicolumn{5}{|c|}{ Total weather and price-risk exposure in a company } \\
\hline $5 €$ & $-2,258,674 €$ & $-1,129,337 €$ & $0 €$ & $1,129,337 €$ & $2,258,674 €$ \\
\hline $10 €$ & $-1,877,348 €$ & $-938,674 €$ & $0 €$ & $938,674 €$ & $1,877,348 €$ \\
\hline $15 €$ & $-1,496,022 €$ & $-748,011 €$ & $0 €$ & $748,011 €$ & $1,496,022 €$ \\
\hline $20 €$ & $-1,114696 €$ & $-557,348 €$ & $0 €$ & $557,348 € €$ & $1,114,696 €$ \\
\hline $25 €$ & $-733,370 €$ & $-366,685 €$ & $0 €$ & $366,685 €$ & $733,370 €$ \\
\hline
\end{tabular}

\section{Weather risk management and the weather-derivatives market}

Traditional risk management from two similar portfolios, in terms of rate return, prefers the one with the lower risk. ${ }^{15}$ The same point of view refers to the value of the company. Many types of market risks such as currency, commodity or interest rate, can be eliminated effectively by financial derivatives. ${ }^{16}$ Marteu and $\mathrm{Holz}^{17}$ demonstrated that the level of volatility in weather indices is on the same level as financial indices. Therefore, there is no reason to hedge a financial risk and bear a weather risk. This holds especially for a company strongly exposed to weather that may receive an extra bonus during credit negotiations as the effect of weather hedging. ${ }^{18}$ Transfer of unwanted weather risk outside the company can be done theoretically, in at least three ways. The first one, normalisation, represents a method of risk transfer to individual customers. Unfortunately, they have less capacity to absorb risk than the capital market and in the long term, because of omitting change in usage patterns, this solution discourages energy saving. ${ }^{19}$ Theoretically, the company may also use classic weather insurance. Vedenov and Barnett ${ }^{20}$ explain that strong spatial correlation in weather events and moral hazards result in high transaction costs for selling and servicing such insurance policies. In fact, such systematic risk is common in financial markets and, if there is no direct financial instrument to transfer

\footnotetext{
${ }^{15}$ Markowitz (1952).

${ }^{16}$ Ederington (1979).

${ }^{17}$ Marteau and Holz (2006).

18 Nicholls (2003).

${ }^{19}$ Foster (2003).

${ }^{20}$ Vedenov and Barnett (2004).
} 
such risk, cross hedging can be used. ${ }^{21}$ All the above problems resulted in practice where the weather derivatives, as a specific type of cross hedging, allow transfer of risk in cheap and efficient ways. ${ }^{22}$ It is worth adding, that in case of multivariate exposure, much like as in the financial market ${ }^{23}$ multi-cross hedging is also possible.

At the present, the weather derivatives market can be divided into two groups: instruments in the exchange market and OTC (Over the Counter) as a non-exchange trade market.

I. Only the Chicago Mercantile Exchange (CME) in the United States qualifies for the first group. Only futures contracts and options on these futures for 41 locations in the world are in regular trade. As far as location is concerned, weather derivatives can be divided into three subgroups: (a) the United States and Canada, (b) Europe, and (c) Japan.

Weather derivatives for locations in the United States and Canada are determined on cumulative temperature indices and Heating Degree Days (HDD) ${ }^{24}$ and Cooling Degree Days (CDD) as defined below:

$$
\begin{aligned}
& \text { Daily } H D D=\text { maximum }\left(65^{\circ} \mathrm{F}-\text { average daily temperature } 24,0\right) . \\
& \text { Daily } C D D=\text { maximum }\left(\text { average daily temperature }-65^{\circ} \mathrm{F}, 0\right) .
\end{aligned}
$$

These indices accumulate during periods of a month or a season (October-April for HDD and April-September for CDD) as quoted at the following North American locations:
(1) Atlanta
(2) Chicago
(3) Dallas
(4) Cincinnati
(5) New York
(6) Philadelphia
(7) Portland
(8) Tucson
(9) Des Moines
(10) Las Vegas
(11) Boston
(12) Houston
(13) Kansas City
(14) Minneapolis
(15) Sacramento
(16) Salt Lake City

\footnotetext{
${ }^{21}$ Anderson and Danthine (1981).

22 Dischel and Barneu (2002).

23 Miller (1986).

${ }^{24}$ An average temperature is calculated as an arithmetic mean from observed maximum and minimum temperatures during 24 hours at a given meteorology station.
} 
(17) Detroit

(18) Baltimore

(19) Calgary

(20) Edmonton

(21) Montreal

(22) Toronto

(23) Vancouver

(24) Winnipeg

The value of one point is US\$20.

We should note that using such temperature indices instead of average temperatures allows for a correct explanation of energy consumption. For example, if the outdoor temperature is a comfortable $65^{\circ} \mathrm{F}$, the consumer usually has no need to warm up the house. If, on the next day, the temperature rises to $70^{\circ} \mathrm{F}$, the consumer will still have no need to turn on the heat. If, however, on the third day, the outdoor temperature drops to $60^{\circ} \mathrm{F}$, it will fall below optimal temperature and the consumer will probably decide to warm the house. Using average temperatures, it is obvious that the average value is $65^{\circ} \mathrm{F}$ and optimal, whereas cumulated HDD equals 5, which demonstrates correctly a need to turn up the heat by $5^{\circ} \mathrm{F}$ during this period. In addition, an index created in this way correlates linearly with energy consumption, which allows us to define the linear pay-off function (Figure 1).

Since 2006, CME has also used monthly snowfall indices (measured in inches) for the period of September-April for Boston and New York. In these contracts one point of the index (one inch) represents US\$200.

The CME quotes similar weather contracts (futures and options) for European locations as well. They are as follows:
(1) London
(2) Paris
(3) Amsterdam
(4) Berlin
(5) Essen
(6) Stockholm
(7) Rome
(8) Madrid
(9) Barcelona

The difference in the two temperature indices lies only in the difference between Celsius and Fahrenheit and CAT (Cumulated Average Temperature) and CDD. For these contracts, the value of one degree-day-point equals $£ 20$ (pounds sterling) while all other parameters are similar.

In 2005, the CME started quoting the more complex Frost Day Index, which counts the number of frosty days, when at least one of the following conditions are met (local time): 7 am temperature is equal or lower than $-3.5^{\circ} \mathrm{C} ; 10$ am temperature is equal or lower than $-1.5^{\circ} \mathrm{C}$; or 7 am and 10 am temperatures are equal or lower than $-0.5^{\circ} \mathrm{C}$. This index is quoted only for Amsterdam in the period of November-March, and one point represents 10,000 euros. 
The CME for Japanese locations quotes futures contracts and options on these futures, which are based on the Monthly Average Temperature (MAT) index, provided by the Japan Meteorology Agency as a Pacific Rim Index. One point of the MAT index represents 2,500 yen.

II. In the second group, the non-exchange market, weather derivatives are written by banks, insurance companies, brokers, hedge funds and other financial companies. The most important feature of these contracts is that they are tailor made for the specific end-user. In practice, this means that such contracts can be written for any location or group of locations and for any measurable weather index. Also, the mechanism in these transactions replicates a wide taxonomy of all known financial derivatives, including exotic ones. Significantly, such transactions can be sold as insurance (with frontier help) or an OTC product with ISDA regulations.

\section{Identification and measurement methods}

The identification of a non-catastrophic weather risk for a company consists of making a list of potential weather events that may have an impact on revenues or costs. The measurement of this risk relies on defining in monetary units the amount of expected losses caused by these events. In general, unfavourable weather conditions can be divided into (1) conditions where parameters and their effects are known, and (2) conditions where parameters and/or their effects are unknown.

Unfavourable weather conditions from the first group appear most often in the construction sector, which leads in delays. ${ }^{25}$ For this group, protection parameters can be settled on the basis of technical standards and specifications of building materials and devices in use or on the value of possible financial penalties in case of delays.

Identification and measurement events from the second group require historical data analysis. However, before starting all calculations, we should add that the financial historical time series ought to be studied to observe if changes in the financial time series were caused only by changes in weather conditions. Usually, factors that may have influence on financial results and should be removed from raw data represent significant change in (1) market share (or number of customers), (2) price of substitute and complementary goods, (3) market price of given product (or service) and (4) tax regulations and laws. In energy sector companies, practical experience shows that the most important and usually sufficient factor is number of customers divided into households, public institutions, and so forth. The most frequent and biggest problem that appears during the above process is availability and quality of financial historical data. In practice, monthly time series for several to a dozen years back is often sufficient to estimate, with high precision, weather exposure for a given company. Usually in weather-risk estimating, only three categories of weather indices (air temperature, precipitation and wind speed) and one financial variable (sales volume, total income or total margin) are used.

\footnotetext{
${ }^{25}$ Connors (2003).
} 


\section{Best Worst approach}

As mentioned before, estimation of weather risk (tick value) can be done by using a few different approaches. Clemmons and Radulski ${ }^{26}$ presented the simplest one, the Best/Worst, approach, where the impact of weather on financial results (in monetary units) can be calculated using the formula below:

$$
\begin{aligned}
\text { Tick value } & =\Delta \text { Sales } / \Delta \text { weather } \\
& =\left(\text { Sales BestYear }_{\text {Bales }} \text { Worst Year }\right) /\left(\text { Index }_{\text {Best Year }}-\text { Index }_{\text {Worst Year }}\right),
\end{aligned}
$$

where Sales $_{\text {Best Year }}$, Sales Worst Year equals the best and the worst financial results (or other financial variable) observed in analysed years, and Index $x_{\text {Best Year }}$, Index Worst Year $_{\text {. }}$ equals values of weather indices in years selected as the best and the worst.

The tick value received from the above formula tells us how much income or other chosen variable increases/decreases, if a given weather index increases/decreases by one point.

\section{Margin coefficient approach}

Forrest $^{27}$ described a very similar approach, margin coefficient, based on the average value of historical gross margins (or other financial variable) divided by historical weather indices:

$$
\text { Tick value }=\sum(\text { gross margin } / \text { weather index }) / n,
$$

where margin equals historical values of total margin or other financial variable (e.g. net profit), weather index equals historical values of a chosen weather index in a given location, and $n$ equals the number of observations.

Notably, only one weather index can be analysed at once in the above two methods, and its selection arises from analysis of the correlation coefficients matrix.

\section{Multivariate linear regression approach}

Clemmons and Radulski ${ }^{28}$ proposed a method based on multivariate linear regression. It is a more advanced approach because it allows estimating more than one significant weather index at a time. An application of this method requires the parameters estimation of the following model:

$$
Y_{t}=\alpha_{0}+\sum_{p=1}^{k} \alpha_{p} x_{p t}+\varepsilon_{t}
$$

\footnotetext{
${ }^{26}$ Clemmons and Radulski (2002).

${ }^{27}$ Forrest (2002).

${ }^{28}$ Clemmons and Radulski (2002).
} 
where $Y_{t}$ equals a time series that represents a financial variable (e.g., monthly income), $x_{p t}$ equals the vector that represents time series for " $k$ " tested weather indices, $\alpha_{p}$ equals the vector of estimated parameters - weather exposure to $p$ th weather variable; they inform what is a tick value for given " $p$ th" index, and $\varepsilon_{t}$ equals residuals, which cannot be explained by weather.

It is important to note that parameters in the above regression models can be estimated using the Ordinary Least Squares (OLS) method, but errors of these parameters cannot, because of some important features like autoregression ${ }^{29}$ or heteroscedastity ${ }^{30}$ existing in weather data. Therefore, standard errors need to be estimated using the Newey-West approach. They can then be jointly used with information criteria for the appropriate selection of regressors in both models.

Received from a robust estimation (OLS with Newey-West errors) list of significant values of weather exposure vector $\left(\alpha_{p}\right)$ informs what the risk exposure is on $p$ th weather variables in monetary units as a tick value for the entire year.

Vedenov and Barnett ${ }^{31}$ presented a similar but non-linear regression model in the construction of weather cover for the agriculture industry. In fact, they also proposed analysing square values of selected weather indices to improve the quality of the model. However, in practice most weather transactions have linear pay-out, making this modification difficult to apply, even on the OTC weather market.

\section{Multivariate linear regression with dummy variables approach}

To include trend and seasonal variables of weather exposure, Eq. (5) should be applied to the well-known multivariate linear regression with dummy variables. ${ }^{32}$ Hence, the complete model takes the following form:

$$
Y_{t}=\sum_{j=0}^{r} \gamma_{j} t^{j}+\sum_{p=1}^{k} \sum_{q=1}^{z-1} \alpha_{q p} m_{q p t} x_{p t}+\varepsilon_{t},
$$

where $m_{q p t} x_{q p t}$ equals dummy variables in given months, $\alpha_{q p}$ equals the vector of estimated parameters that represent risk exposure (tick value) in selected $q$-th month on $p$-th weather index, and $\gamma_{j}$ equals the vector of estimated parameters of trend $(r$-th grade polynomial).

From a theoretical point of view, only the last approach (6) estimates real weather exposure correctly because it takes seasonality into account. For example, if we could add white noise to two perfect seasonal variables (e.g. monthly sales and the monthly HDD index) and use Best/Worst or margin coefficient approaches, then we would find the correct weather exposure. In fact, this correlation would be spurious and would result only from seasonality.

\footnotetext{
${ }^{29}$ Caballero et al. (2001).

${ }^{30}$ Campbell and Diebold (2005).

31 Vedenov and Barnett (2004).

${ }^{32}$ Greene (1993).
} 


\section{Empirical research}

\section{Data and methodology description}

To test the empirical performances of the above approaches, we used the following data:

(a) monthly time series of residential natural gas consumption and yearly time series of number of customers in the state of Illinois (U.S.) for the period January 1989October 2007; data available online at the U.S. Department of Energy website;

(b) daily time series of maximum and minimum temperatures, average wind speeds, and total daily precipitation for the Chicago station (WMO 72530) for a similar period as above; data available online from the National Climatic Data Center of the U.S. National Oceanic and Atmospheric Administration (NOAA). The data obtained (6,939 observations) was cleaned of errors and empty records.

Preliminary analysis demonstrated that only the number of customers has changed significantly in the analysed period and therefore this factor should be removed. Hence, lacking the monthly time series that represented the number of customers, yearly time series and linear interpolation were used to prepare the monthly time series of residential customers. In further calculations, monthly consumption of natural gas per customer was used. Next, the time series were divided in two parts. The first (January 1989 - December 1998) was used for historical data, and the second one (January 1999-October 2007) were used as a period where weather cover was applied. The methods mentioned above were used for finding the appropriate tick value for monthly weather hedging with financial futures where their underlying basis was one or more weather indices, depending on the given approach:

(a) Cumulated Heating Degree Day $\left({ }^{\circ} \mathrm{F}\right)-\mathrm{HDD}[65]$,

(b) Cumulated Average Wind Speed Index (knots) - WSI, and

(c) Cumulated Precipitation Index (inches) - CPI.

Pay-out from a given single- or multi-cross hedging was always in cubic foot (cf) that allowed us to analyse the efficiency of covering losses caused by deviation in natural gas consumption. Expected value as a strike value of a given weather index was accepted as a 10-year average from the selected month, as is often used on the OTC weather market. That allowed us to assume that there is no premium or other costs of entering in long or short positions in the weather-derivatives market. In a similar way, the expected value of natural gas consumption for a specific month was fixed. In the Best-Worst and margin coefficient approaches, tick value was estimated for each month separately. Using the multivariate linear regression, tick value for the appropriate weather index was estimated as a constant value for the entire next year, whereas application of linear regression with dummy variables allowed estimation of tick values for the next year, but with different values for specific months. In all cases, regardless of the approach analysed, during tick value estimation for another period, all previous data was used.

If the weather hedging we analysed represents the "perfect" method (theoretically), then the deviation obtained from the plan (including pay-out from the weather derivative) would equal zero. In fact, for the final deviation from the plan other factors 
Table 2 Selected statistics referring to empirical deviation from the monthly plan with analysed weather covers and without

\begin{tabular}{lrrrrr}
\hline Name of statistics & $\begin{array}{c}\text { Without } \\
\text { weather } \\
\text { cover }\end{array}$ & $\begin{array}{c}\text { Best/ } \\
\text { Worst }\end{array}$ & $\begin{array}{c}\text { Margin } \\
\text { coefficients }\end{array}$ & $\begin{array}{c}\text { Multivariate } \\
\text { linear } \\
\text { regression }\end{array}$ & $\begin{array}{c}\text { Multivariate } \\
\text { linear regression } \\
\text { with dummy } \\
\text { variables }\end{array}$ \\
\hline Maximum negative deviation (cf) & $-8,131.31$ & $-6,525.53$ & $-4,378.84$ & $-4,852.74$ & $-4,894.66$ \\
Maximum positive deviation (cf) & $6,016.88$ & $4,097.97$ & $2,626.64$ & $2,205.40$ & $2,294.77$ \\
Average deviation (cf) & $2,288.00$ & $1,644.55$ & $1,406.49$ & $1,261.56$ & $1,177.69$ \\
Maximum deviation (\%) & 40.76 & 95.44 & 57.76 & 44.48 & 37.51 \\
Average deviation (\%) & 10.41 & 13.40 & 10.24 & 6.80 & 6.13 \\
\hline
\end{tabular}

may also have an impact. This means that weather derivatives in these cases cannot totally cover all losses. However, usually the impact of other factors is small and appears occasionally to accept and check obvious assumptions. If a given weather cover is prepared in the correct way, then application of this cover in the long term leads to significant reduction in deviation from the plan. In order to evaluate the efficiency of all methods, we used the following basic statistics: (a) maximum positive deviation from the monthly plan, (b) maximum negative deviation from the monthly plan and (c) average deviation from the monthly plan. We compared the results we obtained with those without weather cover as a basis for further conclusions.

\section{Results}

In general, usage of weather covers, where values of one point of weather index were fixed with different methods, caused a substantial reduction in deviation from the plan. Table 2 reports selected statistics that confirm that analysis. Analysis of the average deviation reveals that the Best/Worst method gives the poorest results, because in general, deviation from the plan would be lower if such cover would not be applied at all (average deviation (per cent)). A large reduction was observed in hedges where tick values were prepared based on regression models. The multivariate linear regression with dummy variables turned out to be the best approach for finding the appropriate tick value and just a little bit better than the multivariate linear regression. Table 3 presents detailed results from this study with respect to analysed months of heating season.

It should be explained that reduction of maximum or average deviation should have negative values for cases where hedge construction works. In other cases, pay-out from a given cover made the situation worse. Analysing maximum deviations of all methods caused reduction in total values, but in different months with different efficiency. For example, pay-out from weather futures where tick value refers to the Best/Worst approach produced incorrect results in October and made the final deviation much bigger. In fact, except for the last approach, other hedges also worked poorly in this month. Surprisingly, in September, all methods gave an opposite effect and made the weather-cover situation worse. The multivariate linear regression with dummy variables worked as the best approach during the months of February, March and October. In other months, it worked with average efficiency. Also, total reduction was the greatest using this approach and was equal to 16,909 (cf), meaning a reduction of 
Table 3 Empirical reduction of maximum deviation from monthly plan with analysed weather covers

\begin{tabular}{|c|c|c|c|c|c|}
\hline \multirow[t]{2}{*}{ Name of statistics } & \multirow{2}{*}{$\begin{array}{c}\text { Maximum } \\
\text { deviation } \\
\text { without weather } \\
\text { cover }(c f)\end{array}$} & \multicolumn{4}{|c|}{$\begin{array}{l}\text { Reduction of maximum } \\
\text { deviation from plan } \\
(\text { cf })-\Delta \text { of volatility }\end{array}$} \\
\hline & & $\begin{array}{c}\text { Best/ } \\
\text { Worst }\end{array}$ & $\begin{array}{c}\text { Margin } \\
\text { coefficients }\end{array}$ & $\begin{array}{l}\text { Multivariate } \\
\text { linear } \\
\text { regression }\end{array}$ & $\begin{array}{c}\text { Multivariate } \\
\text { linear regression } \\
\text { with dummy } \\
\text { variables }\end{array}$ \\
\hline January & $8,131.31$ & $-4,178.38$ & $-3,752.47$ & $-3,278.58$ & $-3,236.65$ \\
\hline February & $4,917.02$ & $-2,356.71$ & $-2,648.02$ & $-2,795.10$ & $-2,802.61$ \\
\hline March & $4,877.57$ & $-1,745.51$ & $-1,442.47$ & $-1,761.67$ & $-1,847.50$ \\
\hline April & $3,636.42$ & $-5,54.94$ & $-1,676.63$ & $-1,997.29$ & $-1,957.51$ \\
\hline September & 944.65 & 120.02 & 831.05 & 101.39 & 208.52 \\
\hline October & $2,713.43$ & $3,812.10$ & 252.27 & 327.61 & $-\mathbf{5 4 8 . 5 7}$ \\
\hline November & $5,964.23$ & $-4,318.98$ & $-4,372.69$ & $-4,050.13$ & $-3,905.14$ \\
\hline December & $6,016.88$ & $-2,651.02$ & $-3,098.20$ & $-2,739.23$ & $-2,817.15$ \\
\hline $\begin{array}{l}\text { Total reduction in } \\
\text { maximum deviation }\end{array}$ & $37,201.51$ & $-11,873.41$ & $-15,907.17$ & $-16,192.99$ & $-16,906.61$ \\
\hline
\end{tabular}

Values in bold reflect method in given month when reduction was best.

Table 4 Empirical reduction of average deviation from monthly plan with analysed weather covers

\begin{tabular}{|c|c|c|c|c|c|}
\hline \multirow[t]{2}{*}{ Name of statistics } & \multirow{2}{*}{$\begin{array}{c}\text { Average } \\
\text { deviation } \\
\text { without weather } \\
\text { cover }[c f]\end{array}$} & \multicolumn{4}{|c|}{$\begin{array}{l}\text { Reduction of average } \\
\text { deviation from plan } \\
{[c f]-\Delta \text { of volatility }}\end{array}$} \\
\hline & & $\begin{array}{l}\text { Best/ } \\
\text { Worst }\end{array}$ & $\begin{array}{c}\text { Margin } \\
\text { coefficients }\end{array}$ & $\begin{array}{l}\text { Multivariate } \\
\text { linear } \\
\text { regression }\end{array}$ & $\begin{array}{c}\text { Multivariate } \\
\text { linear regression } \\
\text { with dummy } \\
\text { variables }\end{array}$ \\
\hline January & $2,875.04$ & $-1,901.38$ & $-1,896.57$ & $-1,728.82$ & $-1,592.63$ \\
\hline February & $1,570.36$ & -819.97 & -823.94 & -951.04 & -976.77 \\
\hline March & $1,592.41$ & -851.92 & -680.97 & -908.72 & -953.82 \\
\hline April & $1,107.85$ & -292.75 & -677.54 & -747.39 & -637.21 \\
\hline September & 228.40 & 77.12 & 288.58 & 44.09 & 33.75 \\
\hline October & 820.92 & $1,301.66$ & 71.65 & 13.11 & -350.18 \\
\hline November & $1,960.83$ & $-1,507.63$ & $-1,580.87$ & $-1,562.80$ & $-1,498.35$ \\
\hline December & $2,156.92$ & $-1,241.63$ & $-1,364.41$ & $-1,463.48$ & $-1,424.91$ \\
\hline $\begin{array}{l}\text { Total reduction in } \\
\text { average deviation }\end{array}$ & $1,2312.74$ & $-5,236.51$ & $-6,664.07$ & -7305.06 & $-7,400.11$ \\
\hline
\end{tabular}

Values in bold reflect method in given month when reduction was best.

45 per cent. Multivariate linear regression produced slightly worse results. Similar results were obtained from an analysis of the average deviation with and without analysed weather cover (Table 4). The only substantial difference among the analysed models is that only the last approach indicated that all weather indices should be 
used - but not every month. It reflected a crucial change in construction of weather cover, especially in the months of September and October. To compare this, in multivariate linear regression (except for the last year of tests) only the temperature index and wind speed index were relevant. The other methods selected only the monthly temperature index.

\section{Conclusions}

In this paper, we focused on using a monthly time series of natural gas consumption in the state of Illinois (U.S.) and local weather observations to evaluate four different risk measurement methods in the context of building weather covers. This issue is very important because companies that might under- or overestimate weather risk could be suspected of speculating on the weather for profit.

We found that the most accurate approach, the multivariate linear regression model with dummy variables, allows energy companies to include time-variable sensitivity to weather. In general, the simple multivariate linear regression model provided slightly worse results. Basically, the Best/Worst approach should not be used in practice at all. Results from this study clearly show that this approach should be used only in educational purposes or for rough estimates. A better solution is to use the margin coefficient approach, as long as the month is not September or October, during which time this approach gave very poor results. However, both multivariate regression models (the simple one and one with dummy variables) give better results.

We should note that conclusions about the general efficiency of weather-derivative hedging could not be drawn from this study. The reason for this is that in empirical time series, observed deviations often arise from factors other than weather. In this case, efficiency would be higher if this research used:

(a) a real monthly time series of residential number of gas consumption;

(b) weather data for other locations in Illinois, because Chicago does not represent the entire state; and

(c) information about historical failures in gas supplies and other gas cuts.

It would be interesting to see a comparison of the methods considered in this paper for electric or wind energy companies or even for other sectors. A further issue of interest is the length of historical data from a company and its impact on weather-hedging efficiency.

\section{References}

Anderson, R.W. and Danthine, J.P. (1981) 'Cross hedging', Journal of Political Economy 89: 1182-1196. Biello, D. (2002) 'New entrants take chill off weather market', Environmental Finance 11: 14-15.

Brix, A., Jewson, S. and Ziehmann, C. (2005) Weather Derivative Valuation, Cambridge: Cambridge University Press.

Caballero, R., Brix, A. and Jewson, S. (2001) 'Long memory in surface air temperature: Detection, modeling, and application to weather derivative valuation', Climate Research 21: 127-140.

Campbell, S.D. and Diebold, F.X. (2005) 'Weather forecasting for weather derivatives', Journal of the American Statistical Association 100(469): 7-16. 
Clemmons, L. (2002) 'Introduction to weather risk management', in E. Banks (ed) Weather Risk Management: Market, Products and Applications, London: Palgrave, pp. 3-12.

Clemmons, L. and Radulski, D. (2002) 'The economics of weather', in E. Banks (ed) Weather Risk Management: Market, Products and Applications, London: Palgrave, pp. 44-51.

Connors, R.B. (2003) 'Weather derivatives allow construction to hedge weather risk', Cost Engineering 45(3): 21-24.

Corbally, M. and Dang, P.H. (2002) 'Underlying markets and indexes', in E. Banks (ed) Weather Risk Management: Market, Products and Applications, London: Palgrave, pp. 87-103.

Dischel, R.S. (2001) 'Double trouble hedging rainfall and temperature', Energy and Power Risk Management 8: $24-28$.

Dischel, R.S. and Barneu, P. (2002) 'Financial weather contracts and their application in risk management', in R.S. Dischel (ed) Climate Risk and the Weather Market: Financial Risk Management with Weather Hedges, London: Risk Books, pp. 25-42.

Ederington, L.H. (1979) 'The hedging performance of the new futures markets', Journal of Finance 34: 157-170.

Forrest, P. (2002) 'A case study of heating oil partners - weather hedging experience', in R.S. Dischel (ed) Climate Risk and the Weather Market: Financial Risk Management with Weather Hedges, London: Risk Books, pp. 265-279.

Foster, K. (2003) 'The trouble with normalization', Energy and Power Risk Management 7: 22-23.

Greene, H. (1993) Econometric Analysis, New York: Macmillan.

$\mathrm{Ku}$, A. (2001) 'Betting on the weather', Global Energy Business (7-8): 28-32.

Historical meteorological data (daily) in analysed period for Chicago ftp.ncdc.noaa.gov, accessed 12 January 2009.

Malinow, M. (2002) 'End users', in E. Banks (ed) Weather Risk Management: Market, Products and Applications, London: Palgrave, pp. 66-81.

Markowitz, H. (1952) 'Portfolio selection', Journal of Finance 7(10): 77-91.

Marteau, D. and Holz, R. (2006) Is it More Rational to Manage Interest Rate Risk than Weather Risk? paper presented at 2005 WRMA Conference, Toulouse.

McWilliams, D. (2004) Does the Weather Affect the European Economy? paper presented at 2004 WRMA Conference, London.

Miller, S.E. (1986) 'Simple and multiple cross-hedging of millfeeds', Journal of Futures Markets 5(1): 21-28.

Natural gas consumption and number of customers (monthly) for Illinois state in analysed period, http:// www.eia.doe.gov/oil_gas/natural_gas/info_glance/natural_gas.html, accessed 12 January 2009.

Nicholls, M. (2003) 'Fleet Boston credits weather hedgers', Environmental Finance 4: 21-22.

Nicholls, M. (2004) 'Confounding the forecasts', Environmental Finance 10: 5-6.

Saunderson, E. (2004) 'Looking beyond the energy sector', Environmental Finance 3: 20-21.

Skees, J. (2001) 'The potential role of weather markets for U.S. agriculture', The Climate Report 2(4): 4-9.

Starr-McCluer, M. (2000) 'The effects of weather on retail sales', Finance and Economics Discussion 8: $15-28$.

Vedenov, D.V. and Barnett, B. (2004) 'Efficiency of weather derivatives as primary crop insurance instruments', Journal of Agricultural and Resource Economics 29(3): 387-403.

Weinstein, J. (2001) 'Carbon-denominated weather swaps', Environmental Finance 11: 27.

Wojciechowska, K. and Jankowski, P. (2008) The development of the Weather Derivatives Market in Poland within 1989-2008, paper presented at 2008 WRMA Conference, Berlin.

\section{About the Author}

Juliusz Preś has a doctorate in Economics and is Assistant Professor at the West Pomeranian University of Technology (Poland). He is also Director of the Weather Risk Management Department at Consus in Torun. His fields of research focus on implementation and pricing issues of weather derivatives. 